\title{
Experience in the Implementation of Drilling Waste Utilization Technology on the Example of a Large Oil and Gas Region of Russia
}

\author{
Olga Bogdanova ${ }^{1 *}$, Valentina Okmynskaia ${ }^{1}$ \\ 1 Federal State Budget Educational Institution of Higher Education, Industrial University of Tyumen, \\ Volodarskogo 38, 652000 Tyumen, Russia Federal \\ * Corresponding author's e-mail: bogdanovaov1@tyuiu.ru
}

\begin{abstract}
The oil industry is characterized by an intense impact on the environment, which inevitably causes its change. In the production process, the existing state of the environment in the territories of industrial facilities is completely or partially disturbed. Today, the result of the negative environmental impact of the fuel and energy industry on the nature of the regions of northern Russia has resulted in millions of tons of drilling and oil production waste stored in sludge pits and causing colossal damage to the atmosphere, hydro- and lithosphere of the country's oil-producing territories. The aim of this work is to improve the technological process of utilization of drilling waste in the fields with the receipt of an inert building material that does not have a negative impact on the components of the natural environment. In the course of work, based on the analysis of the proposed disposal methods, the most optimal option was selected and a technology for disposal of drilling waste at an oil field was developed, a situational map of the object was presented, and an estimate of the cost of the proposed disposal technology was carried out. Based on the results of the work carried out, a conclusion was made about the effectiveness of the utilization technology under consideration, since it was revealed a decrease in the amount of generated and accumulated waste, a decrease in the costs of maintaining and reclamation of waste accumulation / disposal facilities.
\end{abstract}

Keywords: drilling waste, safe disposal, inert, building material, environmental conservation, waste recycling.

\section{INTRODUCTION}

The number of boreholes in the Tyumen region is growing every year. The reserves of drilling waste are increasing by about one hundred thousand tons annually. Barns containing drilling waste are potential contaminants in the natural environment and must therefore be removed or reclaimed. The scale of possible environmental pollution during drilling is determined by the adopted drilling technology, the location of the drilling site in ecosystems depending on their value and sustainability, the content and quality of work on BW disposal and reclamation.

The negative impact on the environment can be significantly mitigated if the organization carrying out the construction fully implements the set of planned environmental protection measures and maintains an appropriate level of production discipline. Drilling oil and gas wells is associated with the formation of a large amount of drilling waste, which has a significant toxic impact on the environment. The degree of toxic effect depends on their composition and properties, which are largely determined by the characteristics of the drilled rock (Zhabrikov, 2014).

Drilling waste water (BSW), drill cuttings (BS) and waste drilling mud (OBR) contain various substances, the consequences of migration of which into the environment cause disturbances in the ecological balance of biotopes during their interaction with the abiotic environment. At the same time, mainly in the sludge pits, a mixture of BSV, OBR and BSH is stored, or, at best, a mixture of BSV and the mineral part of BSV and OBR cleaning waste. The impact of BSh on the atmosphere occurs through the evaporation of light fractions of oil products from the surface of the 
sludge pit, as well as during the melting of snow on the territory contaminated with sludge (Shamina, 2012). In addition, drying or freezing of the surface layers of drilling waste in pits ensures the spread of fine particles during wind erosion over large areas. At the same time, the introduction of a large amount of finely dispersed mineral particles violates the ecological balance of the territories. The components of the drilling mud and cuttings in the BS are fine and microdispersed hydrophilic particles that are practically not subject to consolidation for a long time, comparable to geological periods. Desorption of pollutants from the surface and from the bulk of particles into the aqueous medium continues for a long time, and the total surface area of the particles provides the significance of this process. The absence of noticeable consolidation of these particles ensures the preservation of the mechanism of pollution of the hydrosphere (Fig. 1).

The negative impact on the environment can be significantly mitigated if the organization carrying out the construction fully implements the set of planned environmental protection measures and maintains an appropriate level of production discipline.

Based on this effect of drilling waste components on the environment, it is strictly forbidden to use waste, regardless of its preliminary treatment, without consolidating it as inert materials, for example, for backfilling of pits, planning works or as overload soil at MSW dumps. Self-purification of the natural environment, especially in conditions of low temperatures of the Far North and a significant slowdown in the rate of natural chemical reactions, takes an extremely long period of time. During the study of existing technologies for the disposal of drilling waste with the receipt of building materials and reclamation mixtures, the following disadvantages were identified:

1. In a number of methods of disposal of drilling waste materials are generated that cannot be used anywhere;

2. A number of utilization methods are characterized by high resource intensity and cost;

3. In a number of ways, secondary waste can be generated due to the disposal of drilling waste and other methods, as well as emissions and discharges, which leads to environmental pollution and littering of the territory;

4. A number of methods are applicable for strictly defined climatic conditions;

5. Some methods require the use of complex and expensive- equipment.

The use of most of the known methods of disposal of drilling waste can entail additional stress on the natural ecosystems of the area, an increase in the factor of constant disturbance of the animal world, and suppression of vegetation. Therefore, the utilization technology under study is not always environmentally and economically viable.

\section{MATERIAL AND METHODS}

Modern technologies make it possible to use drilling waste for the production of a product due to:

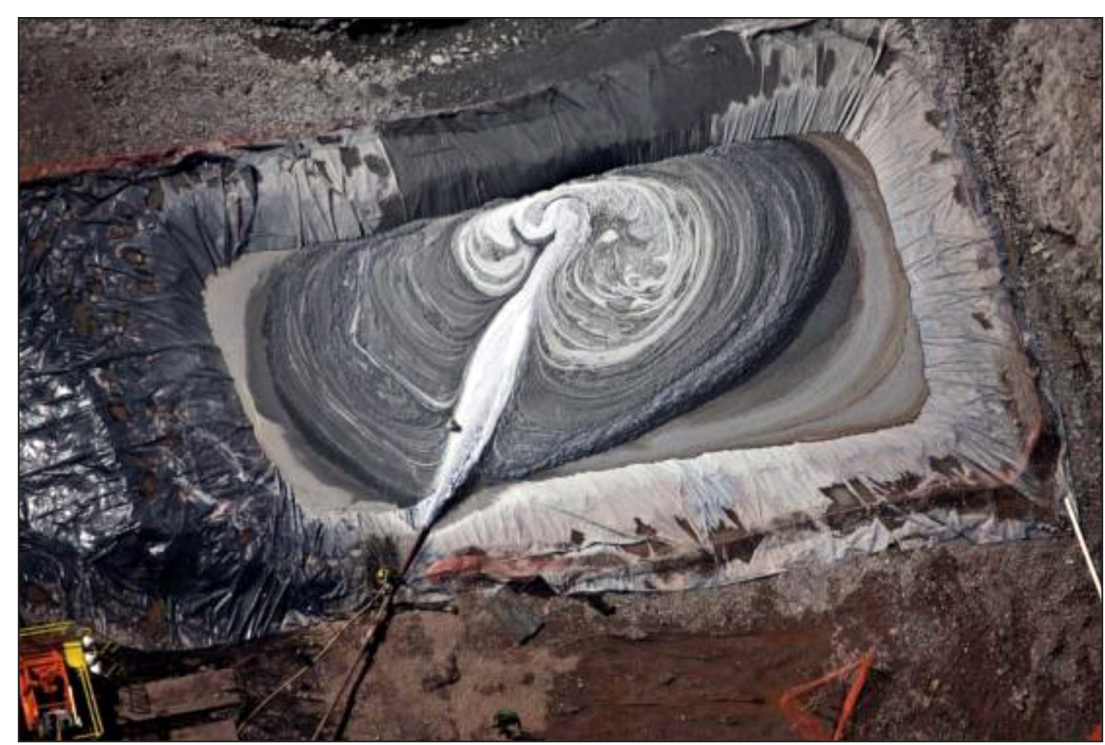

Fig. 1. Discharge of drilling waste into a sludge pit 
- dilution of the feedstock (drilling waste) with natural sandy soils;

- mechanical transformation of drilling waste by mixing, binding and imparting a dispersed structure to the initially amorphous composition of raw materials with a decrease in the number of plasticity;

- sorption and retention of mineral and organic pollutants of the feedstock in the sorbing elements of the resulting product;

- destruction of the initially stable water-retaining system of raw materials and saturation of the entire soil mass with air, ensuring a normal air-water exchange regime, characteristic of mineral soils of the corresponding type (subspecies).

Utilization of drilling waste and obtaining inert building material is carried out by reducing the concentration of pollutants, sorption and neutralization of toxicants in the soil structure, eliminating or minimizing the migration of residual pollutants into the environment to permissible limits. Obtaining building materials implies a set of measures to ensure the receipt of soil with the required characteristics, and the disposal of drilling waste used in the composition. Utilization of drilling waste to obtain inert building materials is carried out by adding filler (sand), reclamation and sorbing components to the mixture of drilling waste, 22 changing the physical and chemical properties of waste both by diluting the concentration of pollutants contained in them, and by binding fine particles and free moisture.
For this purpose, in the production of inert building materials, sand, glauconite, diatomite, quicklime, dolomite flour and gypsum are used (the recipe composition of the introduced components depends on the brand of the material obtained).

Drilling waste (BW) includes: - drilling cuttings during drilling associated with the production of crude oil, natural (associated) gas and gas condensate (FKKO 29112000000);

- spent drilling muds for drilling oil, gas and gas condensate wells (FKKO 29111000000);

- waste water drilling during drilling associated with the extraction of crude oil, natural gas and gas condensate (FKKO 29113000000).

When assessing their toxicity, the presence of petroleum hydrocarbons and toxic components of drilling fluids plays a decisive role. $\mathrm{BOs}$ are the main potential and most largescale environmental pollutants during well construction, since this is the most difficult segment in terms of its volume of formation, different aggregate state, composition, property and hazard class.

For the study, drilling waste was sampled at the Nemchinovskoye field. Geographically, the facility is located $125 \mathrm{~km}$. to the east of the Uvat settlement within the Keumsky license area, Uvatsky district of the Tyumen region of the Russian Federation and belongs to the West Siberian oil and gas province. The field was discovered in 2006 by the Pravdinskaya oil and gas exploration expedition. The location on the map of the field is shown in Figure 2.

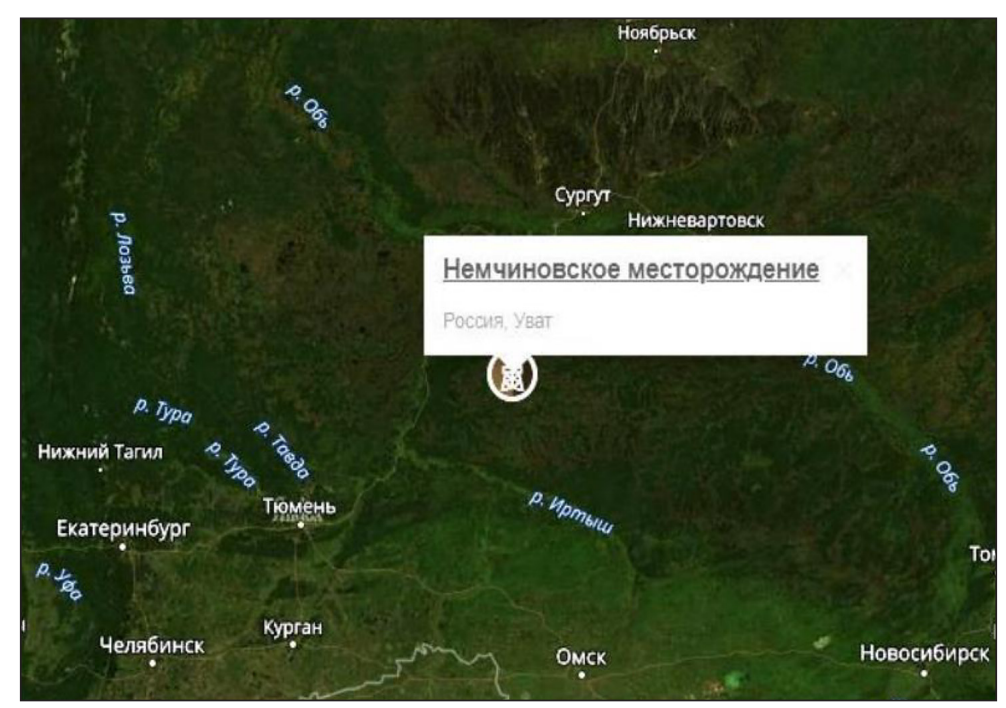

Fig. 2. Nemchinovskoye field on the map 
The field is multi-layer. The implementation of the strategy for the consistent development of the development centers of the Uvat project fields made it possible to start developing the Nemchinovskoye field using the infrastructure of the Tyamkinsky hub, which will achieve a significant synergistic effect. After putting into commercial operation, the Nemchinovskoye field became the sixteenth in the portfolio of the Uvat project. The recoverable reserves of the field are about 4 million tons of oil. Oil is heavy in density, sulfurous, paraffinic, low resinous. The field belongs to the class of average recoverable oil reserves.

The depth of oil well drilling for the period of sampling of drilling waste from the auger conveyor was 3600-3800 meters, the type of drilling mud was salt water-based. For the disposal of drilling waste, it was proposed to use the following components to create 6 variants of potential building mixtures. The component composition of the materials introduced during disposal is presented in Table 1.

Research and measurements were carried out in the laboratories of the departments "Technosphere Safety" and "Building Materials" TIU, as well as in the analytical laboratory of physics, chemistry and mechanics of frozen soils of the cryogenic resources department of the NIPI "Neftegazproekt". Photos of samples are shown in Figure 3.

At the first stage of research, the component composition of inert building materials was developed - drilling waste, sand, natural mineral sorbents (glauconite, diatomite), as well as reclamation additives (dolomite flour, stucco, quicklime).

The analysis of physical, chemical, radiological indicators of drilling waste and construction materials was also carried out, and the cost of the cost of disposal of drilling waste was calculated. According to the results of measurements of the granulometric composition in the obtained materials, the content of physical sand increased several times.
The control sample belonged to loose sands, the obtained inert building materials - cohesive sands (classification of soils by N.A. Kachinsky). The control sample (drilling waste) had the highest moisture content $-49.32 \%$. The moisture values in the obtained inert building materials varied from 27.21 to $30.94 \%$. Building materials had a higher density in comparison with the control sample, this is due to a decrease in the moisture content of the materials, as well as the additional introduction of natural sorbents.

The residual content of petroleum products in the control sample was $25.87 \mathrm{mg} / \mathrm{kg}$, in the materials obtained it varied from 10.60 to $23.98 \mathrm{mg} / \mathrm{kg}$. In general, for all studied samples, this indicator is insignificant, which indicates the safety of inert building materials for the environment. The results of measuring the physicochemical parameters of drilling waste and the obtained samples of building material are presented in Table 2 .

The hydrogen index in materials using gypsum had the lowest values: $8.90-9.10 \mathrm{pH}$ units, the maximum result was obtained for materials using quicklime $-11.08-11.60 \mathrm{pH}$ units. The content of chlorides in the control sample was $0.134 \%$, in building materials decreased and varied from 0.076 to $0.127 \%$. The content of sulfates in the control sample was $0.051 \%$, when the components of the mixture were added, the values of this element were in the range from 0.035 to $0.642 \%$, the maximum concentration was observed when using gypsum (Grades B and E), which is due to an increase in the products of exchange reactions $\left(\mathrm{Na}_{2} \mathrm{SO}_{4}\right)$. In building mixtures, the specific effective activity is higher than in the control sample, this is due to the addition of natural-mineral components with their own specific activity, which leads to an increase in this indicator in the samples of building materials. Samples of grades A, B, C belong to the 1st class of building materials, grades D, E, F - to the 2 nd class.

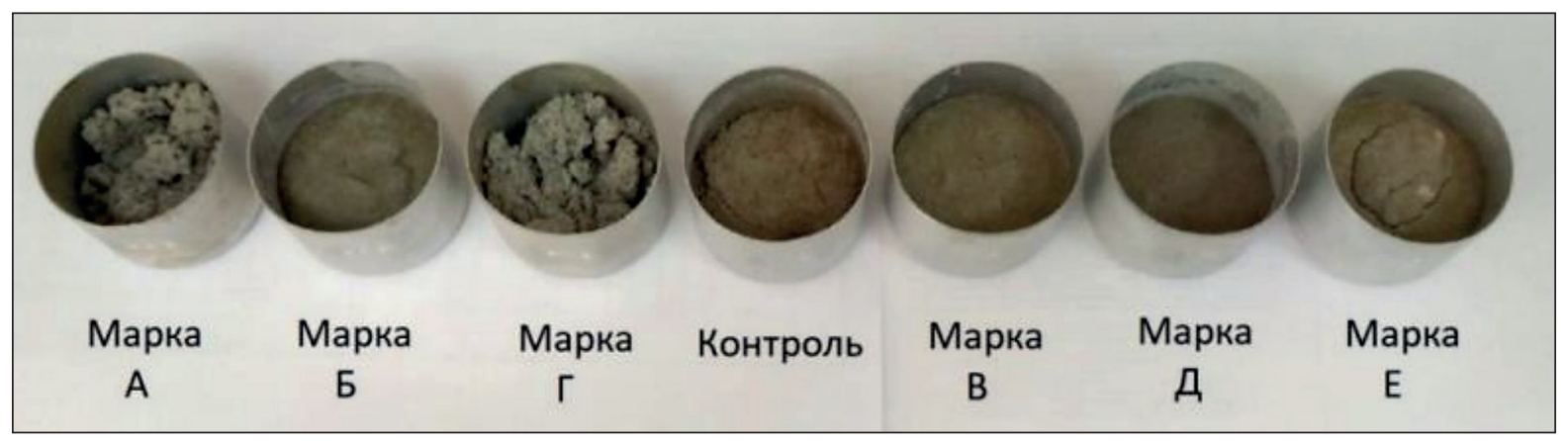

Fig. 3. Samples of the received brands 
Table 1. Component composition of produced building materials

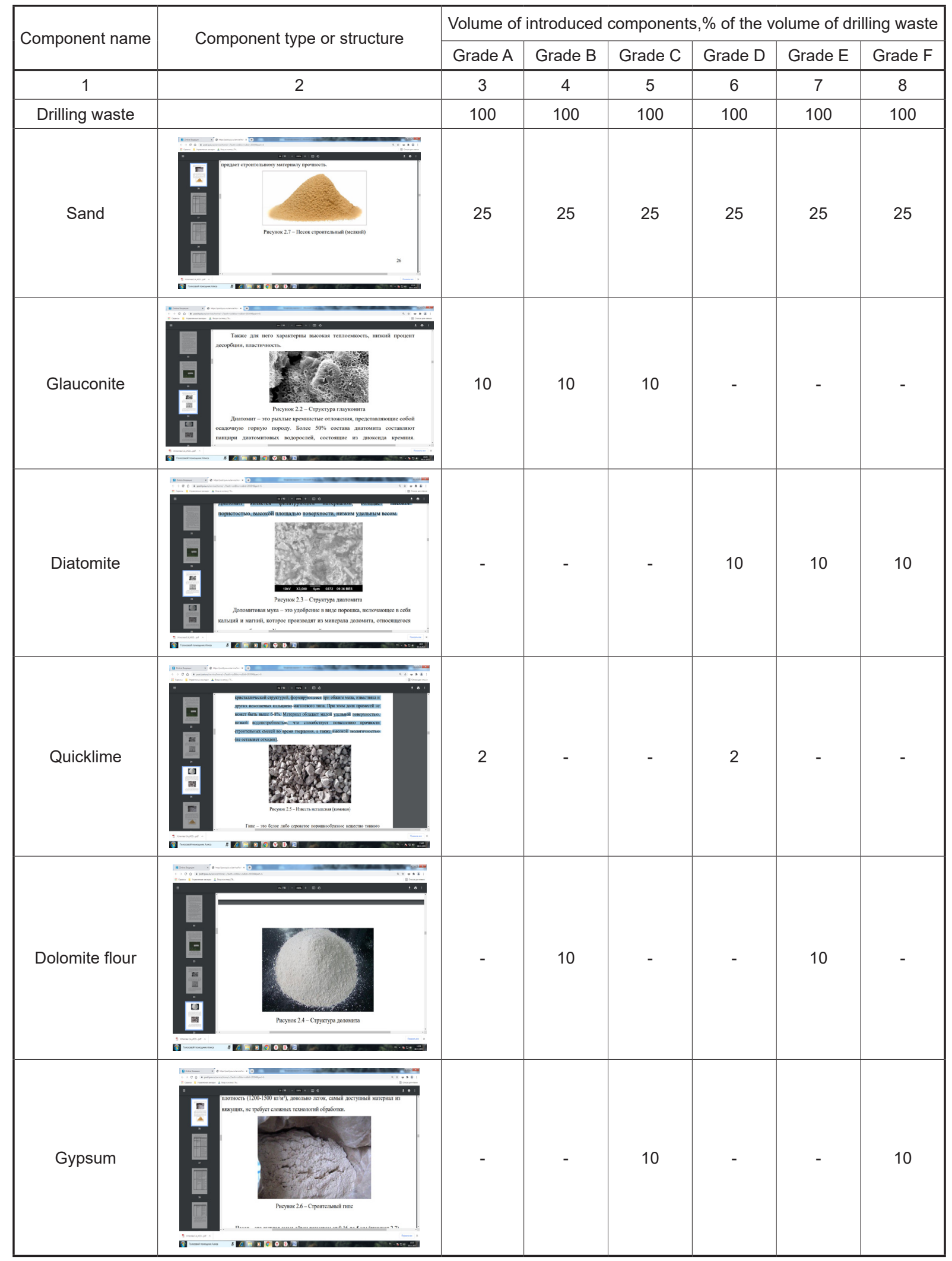

Grade A: drilling waste, sand, glauconite, quicklime. Grade B: drilling waste, sand, glauconite, dolomite flour. Grade C: drilling waste, sand, glauconite, gypsum. Grade D: drilling waste, sand, diatomite, quicklime. Grade E: drilling waste, sand, diatomite, dolomite flour. Grade F: drilling waste, sand, diatomite, gypsum. 
Table 2. Results of measuring the physicochemical indicators of drilling waste and obtained samples of building material

\begin{tabular}{|c|c|c|c|c|c|c|c|}
\hline $\begin{array}{c}\text { Building material } \\
\text { name }\end{array}$ & $\begin{array}{l}\text { Control } \\
\text { sample }\end{array}$ & Grade A & Grade B & Grade C & Grade D & Grade E & Grade F \\
\hline $\begin{array}{l}\text { Recipe composition of } \\
\text { samples }\end{array}$ & $\begin{array}{l}\text { Drilling } \\
\text { waste }\end{array}$ & $\begin{array}{l}\text { BO, sand, } \\
\text { quicklime, } \\
\text { glauconite }\end{array}$ & $\begin{array}{l}\text { BO, sand, } \\
\text { glauconite, } \\
\text { dolomite flour }\end{array}$ & $\begin{array}{l}\text { BO, sand, } \\
\text { gypsum, } \\
\text { glauconite }\end{array}$ & $\begin{array}{l}\text { BO, sand, } \\
\text { quicklime, } \\
\text { diatomite }\end{array}$ & $\begin{array}{c}\text { BO, sand, } \\
\text { dolomite flour, } \\
\text { diatomite }\end{array}$ & $\begin{array}{l}\text { BO, sand, } \\
\text { gypsum, } \\
\text { diatomite }\end{array}$ \\
\hline Humidity, W,\% & 49.32 & 28.26 & 27.21 & 30.01 & 28.19 & 30.37 & 30.94 \\
\hline True density $\rho, \mathrm{g} / \mathrm{cm}^{3}$ & 2.25 & 2.40 & 2.32 & 2.28 & 2.31 & 2.37 & 2.40 \\
\hline $\begin{array}{l}\text { Residual content of oil } \\
\text { products, } \mathrm{mg} / \mathrm{kg}\end{array}$ & 25.87 & 20.35 & 22.13 & 23.32 & 15.57 & 23.98 & 10.60 \\
\hline $\begin{array}{l}\text { Hydrogen exponent, } \\
\text { pH units }\end{array}$ & 9.83 & 11.08 & 9.58 & 9.10 & 11.60 & 9.58 & 8.90 \\
\hline $\begin{array}{l}\text { Chloridion mass } \\
\text { fraction, } \%\end{array}$ & 0.134 & 0.076 & 0.127 & 0.089 & 0.114 & 0.076 & 0.089 \\
\hline $\begin{array}{l}\text { Mass fraction of } \\
\text { sulfation, } \%\end{array}$ & 0.051 & 0.044 & 0.035 & 0.642 & 0.060 & 0.076 & 0.594 \\
\hline $\begin{array}{l}\text { Specific effective } \\
\text { activity of natural } \\
\text { radionuclides, } \mathrm{Bq} / \mathrm{kg}\end{array}$ & $98 \pm 25$ & $121 \pm 26$ & $125 \pm 26$ & $120 \pm 26$ & $350 \pm 46$ & $352 \pm 46$ & $356 \pm 46$ \\
\hline
\end{tabular}

All presented samples do not exceed $1500 \mathrm{~Bq} / \mathrm{kg}$ - the norm for the content of natural radionuclides in building materials. According to the results of the economic evaluation of the samples, the most profitable option can be distinguished - grade D. However, this grade has an alkalinity index of $11.60 \mathrm{pH}$, which is undesirable for a building material. The second most economical sample - Grade E meets all the requirements of building materials. The results of studies on the disposal of drilling waste with the receipt of inert material suggest that these inert building materials can be used for general earthworks.

In general, all the utilization methods obtained meet the requirements of building materials, are safe, environmentally friendly and can be used for their intended purpose.

To describe the technology of utilization of drilling waste, it was decided to take a sample of grade E (drilling waste, sand, diatomite, dolomite flour) as a basis for the manufacture of construction material - the most cost-effective method of waste disposal, all physicochemical indicators for building materials are within norms, which means no harmful effects on the natural environment.

Drilling waste used for the production of building material must meet the original acceptable characteristics at the entrance to the production process. Drilling waste characteristics are determined according to waste passports. In case of lack of initial information in the waste passports, samples are taken and characteristics are determined in a specialized laboratory. Exhaustive physicochemical studies of drilling waste with the preparation of a laboratory analysis protocol should be carried out. The following main parameters are analyzed: chemical composition of the aqueous extract of $\mathrm{BO}(\mathrm{pH}$, residual oil content, chloride and sulfation content); physical and mechanical characteristics (natural moisture, density); granulometric analysis (content of clay particles in BW); radiological analysis.

If the drilling waste does not meet the required parameters, additional preparation of drilling waste is performed before disposal, which includes the ability to regulate certain parameters. An increase in the mass fraction of moisture in drilling waste, if necessary, can be achieved by adding an additional amount of liquid drilling waste (waste drilling mud, drilling waste water, waste water emulsion) or water, including waste, process water.

The decrease in the mass fraction of moisture in the drilling waste can be controlled by pumping out the excess liquid phase, introducing an additional amount of filler, solid phase of drilling waste (drill cuttings) or drying (dewatering) technological additives. It is possible to use filtering (separating) installations, such as filter press, centrifuges and others, as well as drying and thermal installations. Reducing the hazard class, the content of oil and oil products, soluble salts (chlorides, sulfates), the specific effective activity of natural radionuclides (if necessary) is carried out due to the preliminary preparation (treatment) of drilling waste by various methods, such as dilution, washing, extraction, filtration, drying (dehydration), heat treatment, the use of technological additives. The calculation of the cost of the work performed for the disposal of drilling waste consisted of the following indicators: 
1. The cost of the components required to obtain a building material;

2. Delivery of components to the place of application;

3. Labor costs (special equipment, workers).

4. The volume and cost of the introduced components are presented in Table 3

Table 4 shows the estimated cost of drilling waste disposal methods. As a result of calculating the cost of disposal costs, the most economically profitable building material is grade $\mathrm{E}$ - the cost of disposal of $1 \mathrm{~m}^{3}$ of drilling waste is $10,087.46$ rubles.

\section{RESULTS}

The entire production process can be divided into 2 stages:

1. Drilling a well, accompanied by the formation of solid and liquid waste (drill cuttings, waste drilling mud, drilling waste water).

The necessary equipment is delivered to the work site. Drilling includes several operations: deepening the wellbore by regular cleaning and subsequent destruction of the rock, strengthening the rock formations for the integrity and nondestruction of the wellbore, the place between the pipe and the rock is fixed with cement slurry (plugging). The last job is mastering. The last layer of rock is opened on it, the area of the bottom hole is formed, drilling and fluid outflow are carried out. There are 3 wells at the drilling site. The drilling depth of 1 oil well is about 3000 meters, the type of drilling mud is salt water-based. Drilling period for 1 well is 14 days. Drilling is carried out around the clock.

2. Utilization of the generated waste and receipt of inert material with the subsequent elimination of the temporary accumulation of drilling waste.

Utilization of drilling waste can be carried out in three main ways using various combinations of mechanisms: - at specialized sites;

- in the body of objects of accumulation, waste disposal;

- sludge collectors, technological sites for waste accumulation; other earthen excavations;

- other facilities that allow for production work and do not allow drilling waste to enter the environment.

Investigating modern methods of handling drilling waste, as well as the possibilities of the subsoil user in this direction, for a more careful attitude to the natural resources of the region, it was decided to equip a temporary storage of

Table 3. Data for calculating the cost of drilling waste disposal costs (includes costs only for the method itself)

\begin{tabular}{|l|c|c|c|c|}
\hline Component name & Component density, $\mathrm{g} / \mathrm{cm}^{3}$ & $\begin{array}{c}\text { Introduced volume of } \\
\text { the component, } \mathrm{m}^{3}\end{array}$ & $\begin{array}{c}\text { Introduced volume of } \\
\text { the component, } \mathrm{t}\end{array}$ & Cost of 1 ton, rub. \\
\hline Glauconite & 2.5 & 100 & 0.250 & 7000 \\
\hline Diatomite & 1.8 & 100 & 0.180 & 8000 \\
\hline Quicklime & 3.3 & 20 & 0.066 & 2000 \\
\hline Building gypsum & 2.6 & 100 & 0.260 & 4000 \\
\hline Dolomite flour & 1.0 & 100 & 0.100 & 2000 \\
\hline drilling waste & 2.25 & 1000 & 0.225 & - \\
\hline Sand & 1.4 & 250 & 0.350 & - \\
\hline
\end{tabular}

Note * - the cost calculation does not take into account the price of drilling waste and sand, since these components are provided by the customer.

Table 4. Consolidated calculation of the cost of disposal of drilling waste

\begin{tabular}{|l|l|c|c|}
\hline $\begin{array}{c}\text { Building } \\
\text { material name }\end{array}$ & \multicolumn{1}{|c|}{ Recipe composition of samples } & Cost of work, rub. / 1 m & Cost of work, rubles / 1000 m³ \\
\hline Grade A & Drilling waste, sand, quicklime, glauconite & 12709.78 & 12709778.00 \\
\hline Grade B & Drilling waste, sand, glauconite, dolomite flour & 13385.24 & 13385244.79 \\
\hline Grade C & Drilling waste, sand, gypsum, glauconite & 18955.17 & 18955173.65 \\
\hline Grade D & Drilling waste, sand, quicklime, diatomite & 10374.97 & 10374969.72 \\
\hline Grade E & Drilling waste, sand, dolomite meal, diatomite & 11050.44 & 11050436.51 \\
\hline Grade F & Drilling waste, sand, gypsum, diatomite & 16620.37 & 16620365.37 \\
\hline * Transportation costs, drilling waste disposal technology are not taken into account & \\
\hline
\end{tabular}




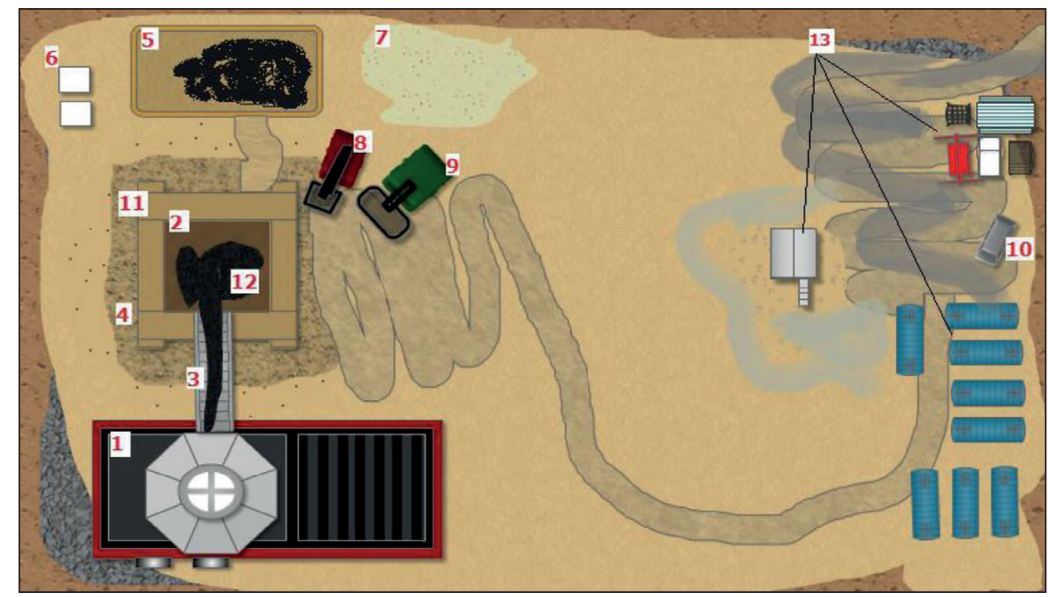

Fig. 4. Situational map of the site for the disposal of drilling waste

drilling waste. Figure 4 shows a situational map of the site for the disposal of drilling waste.

\section{CONCLUSIONS}

In the course of the work, a technology for disposal of drilling waste was developed and described, a situational map of the facility was presented, and the cost of the cost of disposal of drilling waste was calculated. The technology is aimed at solving the following tasks:

- ensuring environmentally safe activities in the field of drilling waste management;

- expansion of the range of materials and their use in order to reduce the use of natural soil;

- reduction of the amount of generated and accumulated waste, their efficient disposal, reduction of costs for maintenance and reclamation of waste accumulation / disposal facilities;

- minimization of environmental impact.

The present technology for producing inert building material in the composition of drilling waste is a complex, most scalable solution for the disposal of drilling waste due to the possibility of using simultaneously the liquid and solid phases of drilling waste, a wide list of possible components, additives, as well as the mechanisms and methods of work used. The resulting inert building material can be used:

- to perform general construction earthworks and work on lands of the construction direction of reclamation in accordance with GOST 17.5.1.02;

- when fixing embankments and slopes of infield roads and areal facilities on the territory of licensed areas;
- when filling the peripheral sections of cluster bases;

- during the construction of embankments of the roadbed and strengthening the soil foundations of construction and other sites, areal facilities;

- when backfilling the bases of well pads and areal objects, backfilling of cutting driveways.

\section{REFERENCES}

1. Kosarevich I.V., Shemetov V.Y., Goncharenko A.P. 1994. Ecology of drilling. Ryabchenko V.I. (Eds.). Minsk: Nauka i tekhnika, 119.

2. Tetelmin V.V., Yazev V.A. 2009. Protection of the environment in the oil and gas complex. Dolgoprudny. Publishing house "Intellect".

3. Kryuchkov V.N., Kurapov A.A. 2012. Assessment of the impact of drilling waste on aquatic organisms. Vestnik Astrakhan. state those. un-that. Series: Fisheries, 1, 61-65.

4. Zhabrikov S.Y. 2014. Building material as a result of drilling waste processing using IMM technology. Theoretical and Applied Aspects of Modern Science, 2(2), 190-199.

5. Pichugin E.A. 2013. Assessment of the impact of drill cuttings on the environment. Young Scientist, 9, 122-123.

6. Shamina V.A. 2012. Drilling waste generation during well construction. Actual Problems of the $\mathrm{Hu}-$ manities and Natural Sciences, 12, 43-45.

7. Big Encyclopedic Polytechnic Dictionary. Multitrade, 2004.

8. Assessment of the environmental impact of the construction of the exploration well N-1 at the Nursultan structure of the "N" site. SED LLP, 2001

9. Oil workers of the Russian Federation. Nemchinovskoye field. Internet news portal. Contains information about deposits. Access mode: http://www. nftn.ru, (in Russian, English). 